\title{
El museo, continente y contenido
}

En la Real Sociedad Económica Sevillana de Amigos del País y organizado por el Gabinete de Arte, se han realizado las "III Jornadas sobre el museo: continente y contenido".

Es la tercera edición de este proyecto que nació con el interés de acercar a los universitarios a una institución cultural de la importancia del museo, que dentro de los planes de la Universidad no está tratada con la profundidad que debiera.

El primer año se abordaron el edificio como contenedor de obras de arte; criterios para formar una colección; los Gabinetes Pedagógicos que posibilitan un conocimiento comprensivo de ésta y el papel del artista como "constructor" de las obras. El segundo año se habló de los estudios de Museografía en Andalucía; los Talleres y actividades de los muse- os y los Centros de Interpretación del patrimonio como una nueva forma de museo.

En las terceras Jornadas, celebradas del 7 al 10 de Marzo de 2000, se ha abierto más el punto de mira, siendo el hilo argumental la ciudad. La Dra. Teresa Pérez Cano, arquitecta, ha analizado el papel de la ciudad como museo, donde coincide lo construido y lo vacío donde se encuentran motivos de entendimiento y desencuentros, puesta en valor y reflexión.

El arquitecto Carlos Tapia, en su conferencia "Espacio identidad: nostalgias del presente", abordó el tema del acercamiento a las posiciones de construcción de lo social. Búsqueda de representación en un mundo donde el instante es presa de sí mismo. Museos, Patrimonio, tiempos cohabitantes, serán los rasgos de una modernidad sobreinformada. Así mismo realizó recorridos por algunos de estos instantes.

Los arqueólogos Reyes Ojeda y Antonio Pérez Paz centraron su conferencia en la musealización y puesta en valor del Patrimonio Arqueológico.

Por último José Antonio Chacón, Director del Centro Andaluz de Arte Contemporáneo, abordó el tema del museo como dinamizador de la vida cultural de la ciudad, apartándose de la vieja idea del museo-mausoleo y dotándolo de una actividad diferente, más de acuerdo con la actualidad. Un museo no contenedor sino espacio de reflexión.

María del Valle Pérez Cano Juan-Ramón Barbancho Rodríguez Directores de las Jornadas

\section{Jornadas Europeas de Patrimonio 2000: "Europa, Patrimonio común"}

Promovidas por el Consejo de Europa en 1991, las Jornadas Europeas de Patrimonio tienen como objetivo promover la sensibilización del público sobre el Patrimonio cultural. En la actualidad colaboran en este evento 44 países y regiones europeas, que, para este año 2000 y en consonancia con la decisión adoptada en la segunda cumbre del Consejo de Europa de Jefes de Estado, promoverán el lema "Europa, Patrimonio Común", con objeto de reforzar la importancia del Patrimonio cultural y natural en la construcción de una Europa común.

En nuestra comunidad, el tema elegido para estas Jornadas es "El Mudéjar en Andalucía" y el día de celebración será el 28 de octubre.
Las Jornadas consistirán en visitas a los monumentos seleccionados que serán guiadas por diversos profesionales (historiadores del arte, arqueólogos, arquitectos, coordinadores de los Gabinetes Pedagógicos, etc.) de las ocho Delegaciones Provinciales de la Consejería de Cultura. Igualmente se llevarán a cabo actividades complementarias como conciertos, conferencias, exposiciones, etc. La toma de conciencia de los jóvenes sobre la importancia del patrimonio como factor de la identidad colectiva europea y su salvaguarda se considera esencial. En este sentido, la participación de los Gabinetes Pedagógicos de Bellas Artes en las actividades programadas con motivo de las Jornadas Europeas en Andalucía proporcionan la adecuada orientación peda- gógica a las visitas guiadas e impulsan el desarrollo de las mismas.

La participación de la Comunidad Autónoma Andaluza en estas Jornadas comenzó en el año 1992, siendo únicamente nuestra comunidad, Cataluña y recientemente el Ministerio de Cultura los participantes españoles en dichas Jornadas. Desde este primer año se ha producido un notable incremento tanto en el número de los monumentos seleccionados como en el de visitantes. Así en 1992 se visitaron dos monumentos por provincia , 58 en el 93, alrededor de 70 en el 94 -con un total de 13.945 visitantes- $y$ en 1995 se seleccionaron 88 monumentos con un total de 30.680 visitantes. 1996 se acercó a las 70 
intervenciones con una asistencia de público cifrada alrededor de los 17.000 visitantes. En 1997 se visitaron 113 castillos y la participación fue de 19.291 visitantes, mientras que en 1998 se visitaron 12 catedrales y 42 museos con una afluencia de público de en torno a los 17.000 visitantes. 1999 alcanzó la cifra de 16.000 .

En los dos primeros años el tema de las Jornadas se centró sobre monumentos integrantes del Patrimonio Histórico andaluz, donde se habían realizado obras de restauración y, en general, poco conocidos o de difícil acceso. En el año 1994 se eligió como motivo "El legado romano en Andalucía" y el 95 realizó una Jornada de Puertas Abiertas sobre el tema "La cultura islámica en Andalucía ". En 1996, el tema elegido fue "Patrimonio y Ciudad", y se realizaron visitas guiadas a monumentos restaurados o en proceso de restauración, así como a distintas excavaciones en curso o ya finalizadas. Los Castillos, como uno de los rasgos más significativos de numerosos pueblos andaluces, centraron en 1997 esta celebración. En 1998 los temas elegidos fueron los Museos y las Catedrales de Andalucía.

Finalmente, el año 1999 fue declarado por la Consejería de Cultura "Año de Velázquez" en conmemoración del IV Centenario del Nacimiento del pintor (BOJA n ${ }^{\circ} 20$ de 16 de Febrero de 1999). En el marco de esta celebración se incluyeron las Jornadas Europeas de Patrimonio, por tratarse de un artista universal, cuya contribución a la historia del arte ha traspasado nuestras fronteras. En este sentido y con motivo de las Jornadas se organizaron en todas las provincias andaluzas una serie de actividades en torno a "El Arte en la época de Velázquez". Sin embargo, la dificultad que entrañaba visitar en todo el territorio de nuestra Comunidad una serie de monumentos vinculados a la vida y obra de este pintor o de sus discípulos y el interés de vinculación a la propuesta del Ministerio de Educación y Cultura aconsejó que las Jornadas de Puertas Abiertas se centraran en la apertura de Monasterios y Conventos de Andalucía.

\section{Jornadas Andaluzas de Difusión}

La VI edición de las Jornadas Andaluzas de Difusión -que se desarrollarán en la primavera de 200 I en Málaga- tendrá un carácter abierto, diferente a las convocatorias anteriores. La actual problemática del Patrimonio Histórico, con importantes experiencias de puesta en valor y de comunicación entre los diferentes agentes sociales, está generando la aparición de numerosos proyectos de distinto carácter, que hace necesario un foro de debate, donde se muestren y discutan las desarrolladas hasta el momento.

Estas Jornadas permitirán a los participantes dar a conocer el desarrollo de proyectos concretos, introducidos por planteamientos teóricos, con conferencias pronunciadas por especialistas en diversas materias. Este foro permitirá contar con una información global de la situación actual.

El plazo para la presentación de los resúmenes (250 palabras) de las comunicaciones terminará el 31 de diciembre de 2000. En una segunda circular se detallarán la sede y fecha concretas y programa de las VI Jornadas y las condiciones concretas de presentación de las comunicaciones seleccionadas.

Este primer foro se destinaría a experiencias desarrolladas por: escuelas-taller, museos locales, entidades locales, comarcales, provinciales, etc. que hayan llevado a cabo puestas en valor del patrimonio, itinerarios culturales, proyectos de animación del patrimonio, etc. Se admitirán con prioridad aquellos proyectos ya realizados y con resultados concretos.

Las Jornadas están dirigidas a los siguientes colectivos:

- Profesionales de la gestión del Patrimonio

- Técnicos de la Administración Pública (nacional, regional o local) con responsabilidad en la gestión y difusión del patrimonio: Directores, Conservadores y Ayudantes de Museos, Directores y técnicos de Centros de Interpretación, Directores-Conservado- res de Conjuntos, Conservadores y ayudantes de Patrimonio, Coordinadores de los Gabinetes Pedagógicos de Bellas Artes, Técnicos de Cultura, gestores de Patrimonio.

- Empresas privadas dedicadas al Patrimonio

- Animadores socioculturales

- Educadores

- Miembros de fundaciones, asociaciones, consorcios y entidades jurídicas relacionas con el Patrimonio.

Paralelamente, se realizará un taller en el que aquellos participantes que lo deseen podrán exponer productos y recursos patrimoniales relacionados con los objetivos de las Jornadas. El plazo de presentación de estos productos es el 31 de diciembre de 2000.

Los temas propuestos son:

I. Museos y Centros de interpretación: nuevas propuestas museológicas y museográficas

2. Animación y Dinamización del Patrimonio Histórico: actividades y resultados

3. Puestas en valor del Patrimonio Histórico

4. Actividades de Difusión del Patrimonio Histórico

5. Turismo Cultural y Patrimonio Histórico

6. La gestión del Patrimonio Histórico como recurso cultural y dinamizador del desarrollo de una región

7. Educación y Patrimonio Histórico: propuestas didácticas

8. Proyectos de cooperación internacional en materia de Patrimonio Histórico.

9. Exposición productos y recursos patrimonionales relacionados con el Patrimonio Histórico:

- Recursos para la dinamización.

- Productos patrimoniales.

\section{Información e inscripciones:}

Servicio de Investigación y Difusión del Patrimonio Histórico.

Dirección General de Bienes Culturales. Consejería de Cultura de la Junta de Andalucía C/ Levíes, 17 4107I SEVILLA

Teléfonos: 955036647/955036615

Fax: 955036621

Correo electrónico: cc_difusion@sistelnet.es 